\title{
Mental Health Impact of COVID-19 among Children and College Students: A Systematic Review
}

\author{
Jad A. Elharake ${ }^{1,2}$ (D) Faris Akbar ${ }^{1,3} \cdot$ Amyn A. Malik ${ }^{1,2} \cdot$ Walter Gilliam $^{4} \cdot$ Saad B. Omer ${ }^{1,2,5,6}$ \\ Accepted: 29 November 2021 \\ (c) The Author(s), under exclusive licence to Springer Science+Business Media, LLC, part of Springer Nature 2021
}

\begin{abstract}
The COVID-19 pandemic led to a worldwide lockdown and school closures, which have placed a substantial mental health burden on children and college students. Through a systematic search of the literature on PubMed and Collabovid of studies published January 2020-July 2021, our findings of five studies on children and 16 studies on college students found that both groups reported feeling more anxious, depressed, fatigued, and distressed than prior to the pandemic. Several risk factors such as living in rural areas, low family socioeconomic status, and being a family member or friend to a healthcare worker were strongly associated with worse mental health outcomes. As schools and researchers discuss future strategies on how to combine on-site teaching with online courses, our results indicate the importance of considering social contacts in students' mental health to support students at higher risk of social isolation during the COVID-19 pandemic.
\end{abstract}

Keywords Mental health $\cdot$ School children $\cdot$ Depression $\cdot$ Education $\cdot$ Public health

\section{Introduction}

The coronavirus disease 2019 (COVID-19) pandemic has adversely impacted countries around the world and overwhelmed the health care infrastructure with over 267 million confirmed cases and 5.3 million deaths (as of December 2021) [1]. Due to the severe threat of the virus, governments enforced strict social distancing measures, including largescale lockdowns, travel limitations, and school closures. While these policies may have been appropriate to contain the outbreak, they have led to unprecedented disruptions in

Jad A. Elharake and Faris Akbar are joint first authors

Jad A. Elharake

jad.elharake@yale.edu

1 Yale Institute for Global Health, Yale University, 1 Church St., New Haven, CT 06510, USA

2 Department of Internal Medicine, Infectious Disease, Yale School of Medicine, New Haven, CT, USA

3 Virginia Polytechnic Institute and State University, Blacksburg, VA, USA

4 Yale Child Study Center, Yale School of Medicine, New Haven, CT, USA

5 Yale School of Public Health, New Haven, CT, USA

6 Yale School of Nursing, Orange, CT, USA people's daily lives while also placing a significant mental health burden.

Interestingly, similar mental health effects were seen in past containment efforts during infectious disease outbreaks, such as the severe acute respiratory syndrome (SARS) in 2003 [2, 3], the 2009 swine flu pandemic [4, 5], and the 2014-2016 Ebola epidemic [6]. Various studies showed that these outbreaks led to a substantial rise in depression, psychological distress, anxiety, and other mental health illnesses among the general public. While there has been plenty of research on the effects of epidemics and pandemics on mental health, particularly adults, very little is known about the impact of disease outbreaks on the mental health of children and college students, especially on a global scale.

As a result of COVID-19, children, adolescent, and college students are experiencing long duration of quarantine, physical isolation from their friends, teachers, and extended family members, and are forced to adapt to a virtual way of learning. Due to this unexpected and forced transition, children and college students may not have adequate academic resources, social contact and support, or a learning-home environment, which may lead to a heightened sense of loneliness, distress, anger, and boredom-causing an increase in negative psychological outcomes. Mental health issues may also arise from the disease itself, such as grief from loss of lives, opportunities, and employment [7-9]. Similar 
psychological effects have been found from wars and previous disease outbreaks [10-13]. Additionally, inequities and disparities in the social determinants of health (e.g., income status, immigrant background, language barrier, parents' educational background, and access to adequate healthcare) may contribute further to the development of psychological distress among children and college students living through the COVID-19 pandemic.

The purpose of this systematic review is to learn about the impact of the COVID-19 pandemic on the mental health of children, adolescents, and college students. Our study will help policymakers, K-12 school administrators, and university leadership understand the need to develop mental health interventions and social support programs to cater to the mental health needs of adolescents and young adults. Identifying practical solutions to address and support adolescents and young adults is incredibly important as students begin to fully transition to in-person learning.

\section{Methods}

\section{Data Collection}

Through a systematic search of the literature on PubMed and Collabovid websites, a review of available peer-reviewed and non-peer reviewed studies (published January 2020-July 2021) was conducted. Two authors of this review independently retrieved studies from the searches using terms relevant to the impact of COVID-19 on the mental health of children, including all possible combinations of the following: (1) youth or child or adolescent, (2) coronavirus or COVID-19, and (3) mental health or depression or stress or post-traumatic stress disorder (PTSD) or insomnia or mood. Similar process was completed in regards to the impact of COVID-19 on the mental health of college students. All possible combinations of the following terms were used to identify relevant college student studies: (1) college students or undergraduate or graduate, (2) coronavirus or COVID-19, and (3) mental health or depression or stress or PTSD or insomnia or mood. Articles that were not primary research studies, including editorials, reviews, comments, viewpoints, correspondences, and other articles lacking a primary data collection, were excluded.

\section{Data Analysis}

Once the relevant studies had been collected, we utilized a data summary analysis. Two authors of this review independently extracted data on basic demographic characteristics and mental health measurements, which were then organized into summary tables.

\section{Results}

\section{Child and Adolescent Studies}

With respect to child and adolescent studies, a total of 2652 articles were found and after removal of 2038 duplicates, 614 studies remained. Of the 614 studies, 609 were excluded due to lack of data and those were not relevant to the purpose of the study. Five studies remained, which were all crosssectional studies, conducted in China, and the variables most commonly measured were depression and anxiety [14-18]. The total number of participants across all studies ranged from 584 to 4342 . See Fig. 1 and Table 1 for more details.

\section{Depression}

Of the five child and adolescent studies, four studies measured depression levels to assess their populations' mental health $[14,15,17,18]$. Chen et al. (2020) study participants' age ranged from 6 to 15 years old, Duan et al. (2020) ranged from 7 to 18 years old, and Tang et al. (2021) ranged from 6 to 17 years old. Xie et al. (2020) study did not include the participants' age information. To measure depression, Duan et al. (2020) and Xie (2020) et al. both used the Child Depression Inventory (CDI) scale, Chen et al. (2020) used the Depression Self-Rating Scale for Children (DSRS-C), and Tang et al. (2021) used the Depression, Anxiety, and Stress Scale (DASS-21). Across the five studies, the percentage of those who met the criteria for depression and/or experienced depressive symptoms ranged from $11.78 \%$ to $22.6 \%$.

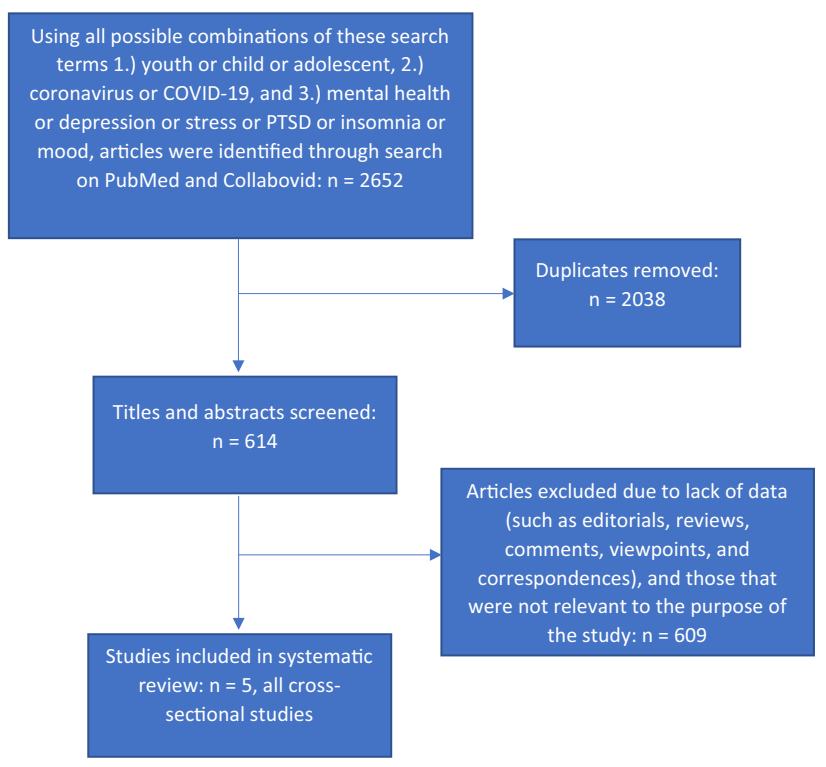

Fig. 1 Systematic review of studies on COVID-19 impact on child mental health 


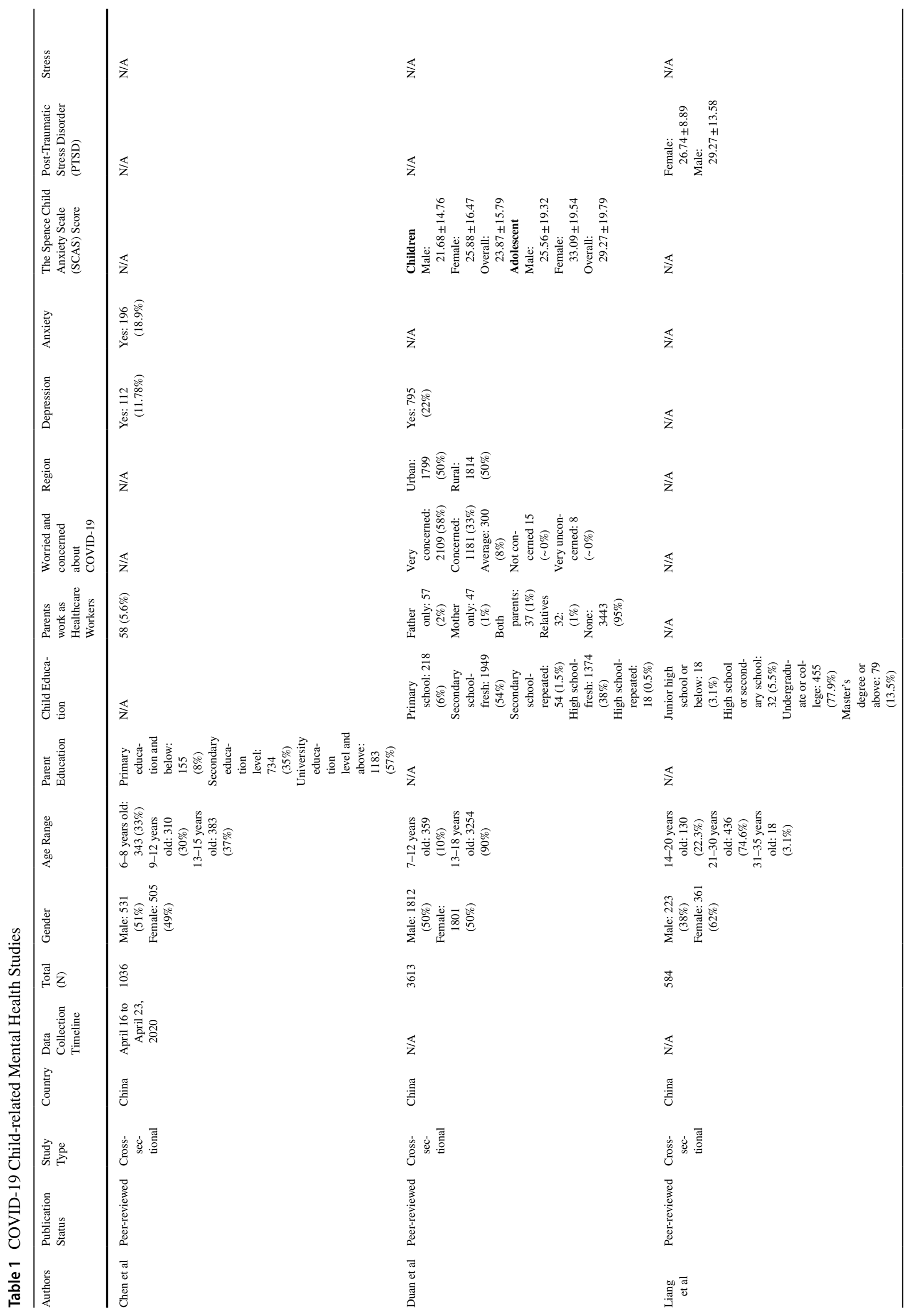









\section{Anxiety}

In the four studies that measured anxiety, Chen et al. (2020) and Xie et al. (2020) both used the Screen for Child Anxiety Related Emotional Disorders (SCARED) scale, Duan et al. (2020) used the Spence Child Anxiety Scale (SCAS), and Tang et al. (2021) used the DASS-21. In the Chen et al. (2020) and Xie et al. (2020) studies, $18.9 \%$ of the sample population met the criteria for anxiety, while $24.9 \%$ of the sample population from the Tang et al. (2021) study experienced anxiety. On the other hand, in the Duan et al. (2020) study, anxiety score for children was $23.87 \pm 15.79$, while the anxiety score for adolescents was $29.27 \pm 19.70$.

\section{PTSD and Stress}

Only two of the five child and adolescent studies, Liang et al. (2020) [16] and Tang et al. (2021), measured stress. The Liang et al. (2020) study measured PTSD using the PTSD Checklist-Civilian Version (PCL-C), while the Tang et al. (2021) study used the DASS-21 to measure stress. The results from the Liang et al. (2021) study showed that the male average score was $29.27 \pm 13.58$ and the female average score was $26.74 \pm 8.89$. Overall, $14 \%$ of the population, which included individuals from 14 to 35 years old, reported having PTSD symptoms. On the other hand, the Tang et al. (2021) study found that $15.2 \%$ of their sample population experienced stress symptoms.

\section{Sociodemographic Characteristics \& Other Factors}

In the Chen et al. (2020) study, it was found that lower parents' educational attainment is associated with increased risk of depression among the children. On the other hand, the Duan et al. (2020) study found that having a family member or friend infected with coronavirus was significantly associated with worse mental health outcomes.

\section{College Student Studies}

Among college student studies, a total of 2921 articles were found and after removal of 2459 duplicates, 462 studies remained. Of the 462 studies, 446 were excluded due to lack of data and those that were not relevant to the purpose of the study. Of the 16 studies remaining, 15 were cross sectional studies and one was a cohort study [16, 19-33]. The total number of participants across the seven studies ranged from 195 to 89,588 college students. The variables most commonly measured in these studies were depression and anxiety, and some studies included other variables such as stress and suicidal thoughts. While a majority of these studies came from China, some were conducted in other countries, including France, India, Jordan, Nigeria, Switzerland, and the United States. See Fig. 2 and Table 2 for more details.

\section{Depression}

Of the 16 college student studies, ten studies evaluated their samples' level of depression [20-23, 25, 26, 28, 30-32]. All ten studies distributed online surveys, but nine studies [20-23, 25, 26, 30-32] were cross-sectional and one [28] was a cohort-study. To measure depression levels, seven studies [20-22, 25, 26, 30, 31] utilized the Patient Health Questionnaire-9 (PHQ-9), Elmer et al. (2020) used the Center for Epidemiologic Studies Depression scale, Ojewale (2020) study used the Hospital Anxiety Depression Scale (HADS), and Wathelet et al. (2021) used the 13-item Beck Depression Inventory. Across all studies, the percentage of college students who reported moderate or severe level of depression ranged from $4.18 \%$ to $50.3 \%$.

\section{Anxiety}

In the 14 studies that measured anxiety levels [19-32], Son et al. (2020) asked general anxiety questions, Ojewale (2020) used the Hospital Anxiety Depression Scale (HADS), Wathelet et al. (2021) used the 20-item State-Trait Anxiety Inventory, two studies [21, 27] used the Self-rating Anxiety Scale (SAS), and the other nine studies $[19,20,22,25,26$, 28-31] used the Generalized Anxiety Disorder-7 (GAD-7). Across all studies, the percentage of college students who reported experiencing some level of anxiety due to the COVID-19 pandemic ranged from $7.7 \%$ to $79.66 \%$.

\section{Stress}

In the five studies that measured stress, Son et al. (2020) and Wang et al. (2020) asked general questions about stress levels, Elmer et al. and Wathelet et al. (2021) used the Perceived Stress Scale-10 (PSS-10), and Ma et al. (2021) used the impact of event scale-6 (IES-6) to measure stress. Across the five studies, the percentage of college students who reported experiencing increased levels of stress due to the COVID-19 pandemic ranged from $24.7 \%$ to $71 \%$.

\section{PTSD}

Only three studies, Chi et al. (2020), Sun et al. (2021), and Liang et al. (2020), assessed PTSD levels among college students. The Chi et al. (2020) study used the abbreviated PTSD Checklist (PCL) and found that $30.8 \%$ of its participants had clinically relevant PTSD, while the Sun et al. (2021) study used the Impact of Events Scale (IES) and found that 67.05\% of its participants reported traumatic stress symptoms. The 
Liang et al. (2020) study was described above in the child and adolescent studies section.

\section{Sociodemographic Characteristics and Other Factors}

In the Sun et al. (2021) study, researchers found that family financial stress due to COVID-19 consistently predicted psychiatric symptoms. In the Ojewale (2020) study, there was a higher prevalence of anxiety and depression among college students who are unable to afford three meals per day, which highlights a similar financial burden due to COVID-19 as the Sun et al. (2021) study. Furthermore, in the Cao et al. (2020) study, it was found that low family income, having relatives or friends infected with COVID-19, and living in rural areas were risk factors for increased levels of anxiety among college students and overall worse mental well-being.

The last study, which did not fit in one of the main themes above, was the Moghe et al. (2020) study. This was a crosssectional study in India and it found that over $75 \%$ of its sample felt fatigued and over $80 \%$ of individuals felt sad and empty due to the COVID-19 pandemic.

\section{Discussion}

Our systematic review of five studies on children and 16 studies on college students found evidence highlighting the adverse mental impact of the COVID-19 pandemic. Children and college students reported feeling more anxious, depressed, fatigued, and distressed than prior to the pandemic. Additionally, several risk factors such as living in rural areas, low family socioeconomic status, being a family member or friend to a healthcare worker, and knowing someone who was infected with COVID-19 were strongly associated with worse mental health outcomes. Understanding the mental health effects of the COVID-19 pandemic on children and college students is important for policymakers and university administrators to create timely, effective, and country-specific interventions that will improve children's and college students' mental well-being and prevent more psychological illnesses from developing. Identifying effective solutions and interventions to address and support the mental health needs of adolescents and college students must be prioritized as children and students begin to fully transition to in-person learning.

All studies consistently identified a clear relationship between adolescents' and young adults', particularly college students, mental health status and the onset of the COVID19 pandemic. This association may be explained by the international lockdown measures (e.g., school closures, nonessential business shutdowns, and enforced social distancing measures) that were implemented to reduce the spread of the virus, which led to an increase in social isolation amongst the general public [34]. With respect to mental health, solitude and prolonged state of physical isolation have been linked to increases in depression, anxiety, and suicidal ideation [35, 36]. According to the United Nations Educational, Scientific, and Cultural Organization, 138 countries had implemented national school closures due to COVID-19 by May 2020, which impacted more than one billion children and young adults-approximately $80 \%$ of the global student population [37]. With these measures in place, one-third of adolescents reported high levels of loneliness and almost half of young adults reported being lonely while quarantining [38-40]. Global school closures forced K-12 and college students to adapt to online learning, but also separated students from having in-person interactions with teachers, classmates, and friends.

While social distancing measures are vital for containing the spread of COVID-19 and is necessary to ease the burden on health systems, policymakers and university administrators must work with public health experts to identify psychological services and initiatives to provide mental health support to adolescents and college students. One intervention recently studied that may be used in pre-school settings is the early childhood mental health consultation (ECMHC), which has been found to significantly lower ratings of hyperactivity, restlessness, externalizing behaviors, and problem behaviors among children under 6 years old [41-44]. ECMHC is a preventative intervention that places mental health consultants in early childcare settings and pairs these consultants with families to address a child's individual needs and increase their social and emotional health [42,



Fig. 2 Systematic review of studies on COVID-19 impact on college student mental health 


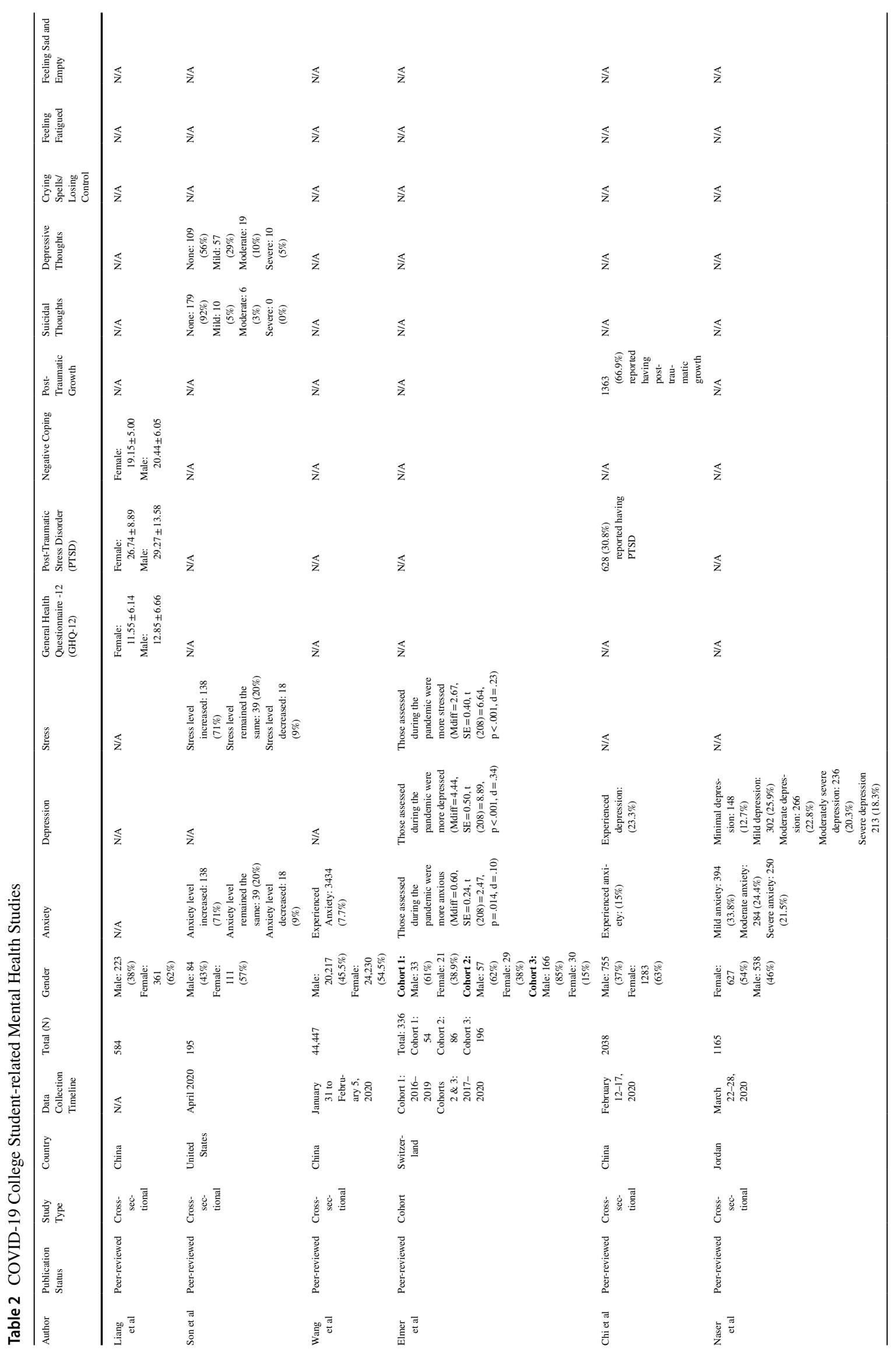




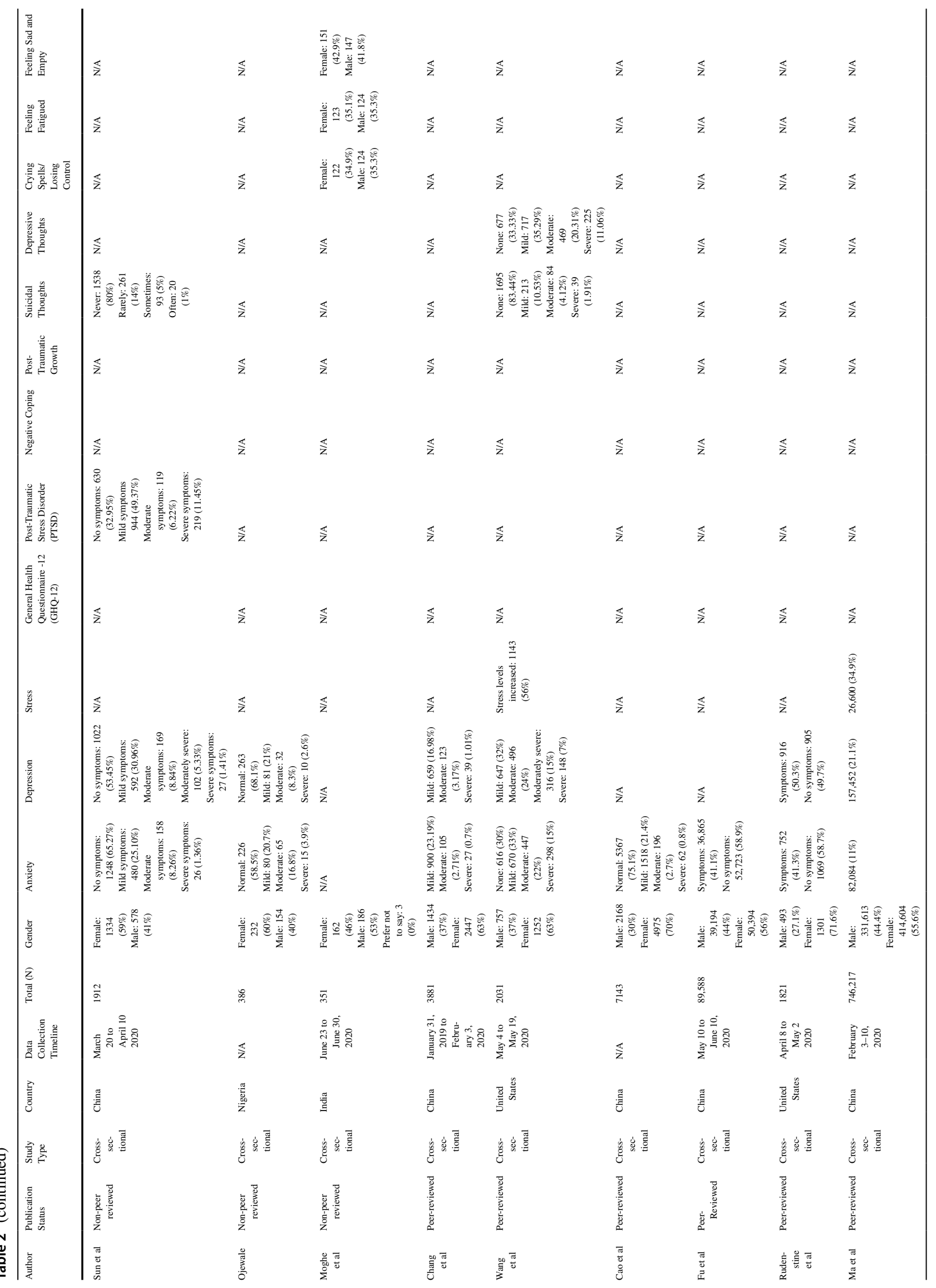







When COVID-19 social distancing measures were imposed, many businesses were forced to shut down-leaving many adults unemployed for several months [56]. As a result, college students who worked several jobs to pay for tuition and/ or housing were also laid off-adding economic pressure during an already overwhelming time. Children and adolescents, on the other hand, whose family income status is low, had to rely on the scarce academic and technological resources that exist in their households as they transitioned to virtual learning. Schools that are closed for a long period of time can have significant health consequences for children living in poverty. This will exacerbate food insecurity as many low-income students rely on school meals. Studies show that food insecurity is associated with low educational performance, while school lunch is associated with high educational attainment $[57,58]$. This highlights an important global health concern as children are not only experiencing worse mental health outcomes, but their physical health is also being negatively impacted.

Our systematic review also found that being a family member or friend to a healthcare worker and knowing someone who was infected with COVID-19 were strongly associated with worse mental health outcomes, particularly anxiety. Because healthcare workers are on the frontlines in combatting COVID-19 as they treat patients on a frequent basis, children and young adults who are in close contact with these healthcare professionals may be even more worried about contracting the virus, given their level of direct contact. Mental health services should consider the need of family members and friends of health care workers. This effective communication strategy can also be applied to those who reported feeling more anxious because they know someone who was infected with COVID-19. Additionally, although the COVID-19 pandemic has resulted in a widespread forced adoption of telehealth services to deliver psychiatric and mental health support [59-61], healthcare providers should identify ways to cater more healthcare workers, those infected by COVID-19, and the families of these groups through employer benefits and insurance companies. Moreover, this identifies the need for more research to investigate ways to improve preparedness for rapid virtualization of psychiatric counseling and tele-psychiatry.

Based on our systematic review, we identified several gaps in the literature that should be addressed with additional research on child and college student mental health during the COVID-19 pandemic. First, there is a need for interventional studies, as all of the studies we found were non-interventional, to evaluate direct impacts of mental health treatment or preventive measures on mental illnesses. Second, more studies should be nationally or regionally representative so that their results can be applied to the broader populations. Third, because there are plenty of cross-sectional studies, researchers should consider conducting more longitudinal cohort studies to identify potential changes in mental health outcomes over time. Fourth, researchers must also factor in pre-existing mental disorders among their sample populations to fully and more accurately assess participants' mental health. Lastly, there is a need to investigate more mental health variables, beyond the common ones such as depression, anxiety, stress, and PTSD, and instead, also assess child and college student suicide ideation, insomnia, coping, and quality of life.

\section{Strengths and Limitations}

As potential limitations, our review did not include studies in low- and low-middle income countries and most studies were conducted in China. In addition, because most of the studies were cross-sectional, associations cannot be inferred. There were also more college student studies identified than children-related studies. Furthermore, three of the 16 college student studies were not peer-reviewed. However, even if we did exclude these non-peer reviewed studies from our systematic review, our overall findings would remain the same. Some strengths of our review are it answers a more expansive question (as opposed to other similar reviews [62-65]), it is focused on COVID-19, and covers a large date range, which makes our review one of the first systematic reviews to have these qualities.

\section{Conclusion}

Overall, our systematic review identified a relationship between the COVID-19 pandemic and adverse mental health problems in children and college students. Additionally, individuals who lived in rural areas, low-income populations, being a family member or friend to a healthcare worker, and knowing someone who was infected with COVID-19 were all associated with worse mental health outcomes. As universities and researchers discuss future strategies on how to combine on-site teaching with online courses, our results indicate the importance of considering social contacts for students' mental well-being and offer starting points to identify and support students at higher risk of social isolation and negative psychological effects. Given the mental health impact of the COVID-19 pandemic, there needs to be urgent interventions, through telehealth, to address the rise in mental health illnesses among children and young adults. However, in the long-run, it is vital for policymakers to prepare for future pandemics by having mechanisms and safety-nets for mental health preventive measures.

\section{Summary}

In summary, our systematic review of five studies on children and 16 studies on college students found that children and college students reported feeling more anxious, 
depressed, fatigued, and distressed than prior to the pandemic. Several risk factors such as living in rural areas, low family socioeconomic status, and being a family member or friend to a healthcare worker were strongly associated with worse mental health outcomes. As schools and researchers discuss future strategies on how to combine on-site teaching with online courses, our results indicate that understanding the mental health effects of the COVID-19 pandemic on children and college students is important to create timely, effective, and country-specific interventions that will improve children's and college students' mental well-being.

Funding All phases of this study were supported by the Yale Institute for Global Health.

\section{Declarations}

Conflict of interest The authors declare that they have no conflict of interest.

\section{References}

1. Johns Hopkins University. COVID-19 Dashboard by the Center for Systems Science and Engineering (CSSE) at Johns Hopkins University (JHU) 2021 [cited 2020 December]. Available from: https://coronavirus.jhu.edu/map.html.

2. Peng EY, Lee MB, Tsai ST, Yang CC, Morisky DE, Tsai LT et al (2010) Population-based post-crisis psychological distress: an example from the SARS outbreak in Taiwan. J Formos Med Assoc 109(7):524-32. https://doi.org/10.1016/s0929-6646(10)60087-3

3. Hawryluck L, Gold WL, Robinson S, Pogorski S, Galea S, Styra R (2004) SARS control and psychological effects of quarantine, Toronto, Canada. Emerg Infect Dis 10(7):1206-12. https://doi. org/10.3201/eid1007.030703

4. Yeung NCY, Lau JTF, Choi KC, Griffiths S (2017) Population responses during the pandemic phase of the influenza A(H1N1)pdm09 epidemic, Hong Kong, China. Emerg Infect Dis 23(5):813-5. https://doi.org/10.3201/eid2305.160768

5. Taha SA, Matheson K, Anisman H (2014) H1N1 was not all that scary: uncertainty and stressor appraisals predict anxiety related to a coming viral threat. Stress Health 30(2):149-57. https://doi. org/10.1002/smi.2505

6. Jalloh MF, Li W, Bunnell RE, Ethier KA, O'Leary A, Hageman $\mathrm{KM}$ et al (2018) Impact of Ebola experiences and risk perceptions on mental health in Sierra Leone, July 2015. BMJ Glob Health 3(2):e000471. https://doi.org/10.1136/bmjgh-2017-000471

7. Bertuccio RF, Runion MC (2020) Considering grief in mental health outcomes of COVID-19. Psychol Trauma 12(S1):S87-s9. https://doi.org/10.1037/tra0000723

8. Gesi C, Carmassi C, Cerveri G, Carpita B, Cremone IM, Dell'Osso L (2020) Complicated grief: what to expect after the coronavirus pandemic. Front Psychiatry 11:489. https://doi.org/ 10.3389/fpsyt.2020.00489

9. Mortazavi SS, Assari S, Alimohamadi A, Rafiee M, Shati M (2020) Fear, loss, social isolation, and incomplete grief due to COVID-19: a recipe for a psychiatric pandemic. Basic Clin Neurosci 11(2):225-32. https://doi.org/10.32598/bcn.11.covid 19.2549.1
10. Morina N, von Lersner U, Prigerson HG (2011) War and bereavement: consequences for mental and physical distress. PLoS One 6(7):e22140. https://doi.org/10.1371/journal.pone. 0022140

11. Thabet A, Tawahina AA, Sarraj E, Vostanis P (2013) Death anxiety, PTSD, trauma, grief, and mental health of Palestinians victims of War on Gaza. Health Care: Curr Rev. https://doi.org/10. 4172/hccr.1000112

12. Van Bortel T, Basnayake A, Wurie F, Jambai M, Koroma AS, Muana AT et al (2016) Psychosocial effects of an Ebola outbreak at individual, community and international levels. Bull World Health Organ 94(3):210-4. https://doi.org/10.2471/blt.15.158543

13. Tucci V, Moukaddam N, Meadows J, Shah S, Galwankar SC, Kapur GB (2017) The forgotten plague: psychiatric manifestations of Ebola, Zika, and emerging infectious diseases. J Glob Infect Dis 9(4):151-6. https://doi.org/10.4103/jgid.jgid_66_17

14. Chen F, Zheng D, Liu J, Gong Y, Guan Z, Lou D (2020) Depression and anxiety among adolescents during COVID-19: A crosssectional study. Brain Behav Immun 88:36-8. https://doi.org/10. 1016/j.bbi.2020.05.061

15. Duan L, Shao X, Wang Y, Huang Y, Miao J, Yang X et al (2020) An investigation of mental health status of children and adolescents in china during the outbreak of COVID-19. J Affect Disord. 275:112-8. https://doi.org/10.1016/j.jad.2020.06.029

16. Liang L, Ren H, Cao R, Hu Y, Qin Z, Li C et al (2020) The effect of COVID-19 on youth mental health. Psychiatr Q 91(3):841-852

17. Tang S, Xiang M, Cheung T, Xiang Y-T (2021) Mental health and its correlates among children and adolescents during COVID19 school closure: The importance of parent-child discussion. J Affect Disord 279:353-360

18. Xie X, Xue Q, Zhou Y, Zhu K, Liu Q, Zhang J et al (2020) Mental health status among children in home confinement during the coronavirus disease 2019 outbreak in Hubei Province, China. JAMA Pediatr 174(9):898-900. https://doi.org/10.1001/jamapediatrics. 2020.1619

19. Cao W, Fang Z, Hou G, Han M, Xu X, Dong J et al (2020) The psychological impact of the COVID-19 epidemic on college students in China. Psychiatry Res 287:112934. https://doi.org/10. 1016/j.psychres.2020.112934

20. Chang J, Yuan Y, Wang D (2020) Mental health status and its influencing factors among college students during the epidemic of COVID-19. Nan Fang Yi Ke Da Xue Xue Bao. 40(2):171-6. https://doi.org/10.12122/j.issn.1673-4254.2020.02.06

21. Chi X, Becker B, Yu Q, Willeit P, Jiao C, Huang L et al (2020) Prevalence and psychosocial correlates of mental health outcomes among chinese college students during the coronavirus disease (COVID-19) pandemic. Front Psychiatry. 11:803. https://doi.org/ 10.3389/fpsyt.2020.00803

22. Naser AY, Dahmash EZ, Al-Rousan R, Alwafi H, Alrawashdeh HM, Ghoul I et al (2020) Mental health status of the general population, healthcare professionals, and university students during 2019 coronavirus disease outbreak in Jordan: A cross-sectional study. Brain Behav 10(8):e01730. https://doi.org/10.1002/brb3. 1730

23. Ojewale LY. Psychological state, family functioning and coping strategies among students of the University of Ibadan, Nigeria, during the COVID -19 lockdown. medRxiv. 2020:2020.07.09.20149997. Doi:https://doi.org/10.1101/2020. 07.09.20149997.

24. Son C, Hegde S, Smith A, Wang X, Sasangohar F (2020) Effects of COVID-19 on College Students' Mental Health in the United States: Interview Survey Study. J Med Internet Res. 22(9):e21279. https://doi.org/10.2196/21279

25. Sun S, Goldberg SB, Lin D, Qiao S, Operario D (2021) Psychiatric symptoms, risk, and protective factors among university students 
in quarantine during the COVID-19 pandemic in China. Global Health 17(1):15. https://doi.org/10.1186/s12992-021-00663-X

26. Wang X, Hegde S, Son C, Keller B, Smith A, Sasangohar F (2020) Investigating mental health of US college students during the COVID-19 pandemic: cross-sectional survey study. J Med Internet Res. 22(9):e22817. https://doi.org/10.2196/22817

27. Wang ZH, Yang HL, Yang YQ, Liu D, Li ZH, Zhang XR et al (2020) Prevalence of anxiety and depression symptom, and the demands for psychological knowledge and interventions in college students during COVID-19 epidemic: A large cross-sectional study. J Affect Disord 275:188-93. https://doi.org/10.1016/j.jad. 2020.06.034

28. Elmer T, Mepham K, Stadtfeld C (2020) Students under lockdown: Comparisons of students' social networks and mental health before and during the COVID-19 crisis in Switzerland. PLoS One 15(7):e0236337. https://doi.org/10.1371/journal.pone. 0236337

29. Fu W, Yan S, Zong Q, Anderson-Luxford D, Song X, Lv Z et al (2021) Mental health of college students during the COVID-19 epidemic in China. J Affect Disord 280:7-10

30. Ma Z, Zhao J, Li Y, Chen D, Wang T, Zhang Z et al (2020) Mental health problems and correlates among 746217 college students during the coronavirus disease 2019 outbreak in China. Epidemiol Psychiatr Sci. https://doi.org/10.1017/S2045796020000931

31. Rudenstine S, McNeal K, Schulder T, Ettman CK, Hernandez M, Gvozdieva K et al (2021) Depression and anxiety during the covid-19 pandemic in an urban, low-income public university sample. J Trauma Stress 34(1):12-22

32. Wathelet M, Duhem S, Vaiva G, Baubet T, Habran E, Veerapa E et al (2020) Factors associated with mental health disorders among university students in France confined during the COVID19 pandemic. JAMA Network Open 3(10):e2025591

33. Moghe K, Kotecha D, Patil M. COVID-19 and Mental Health: A Study of its Impact on Students. MedRxiv. 2020.

34. Viner RM, Russell SJ, Croker H, Packer J, Ward J, Stansfield $\mathrm{C}$ et al (2020) School closure and management practices during coronavirus outbreaks including COVID-19: a rapid systematic review. Lancet Child Adolesc Health 4(5):397-404. https://doi. org/10.1016/s2352-4642(20)30095-x

35. Leigh-Hunt N, Bagguley D, Bash K, Turner V, Turnbull S, Valtorta $\mathrm{N}$ et al (2017) An overview of systematic reviews on the public health consequences of social isolation and loneliness. Public Health 152:157-71. https://doi.org/10.1016/j.puhe.2017.07.035

36. Usher K, Bhullar N, Jackson D (2020) Life in the pandemic: social isolation and mental health. J Clin Nurs 29(15-16):2756-7. https://doi.org/10.1111/jocn. 15290

37. UNESCO. Education: From disruption to recovery: UNESCO; 2021 [cited 2021]. Available from: https://en.unesco.org/covid19/ educationresponse.

38. Lim M. Achieving resilience during COVID-19: psycho-social risk \& protective factors amidst a pandemic in adolescents: Mental Health Research Matters; 2020 [cited 2021]. Available from: http://mentalhealthresearchmatters.org.uk/achieving-resilienceduring-covid-19-psycho-social-risk-protective-factors-amidst-apandemic-in-adolescents/.

39. Young Minds. Coronavirus: Impact on young people with mental health needs 2020 [cited 2021]. Available from: https://young minds.org.uk/media/3708/coronavirus-report_march2020.pdf.

40. Mental Health Foundation. Loneliness during coronavirus. MentalHealth. 2020

41. Gilliam WS, Maupin AN, Reyes CR (2016) Early Childhood Mental Health Consultation: Results of a Statewide RandomControlled Evaluation. J Am Acad Child Adolesc Psychiatry. 55(9):754-61. https://doi.org/10.1016/j.jaac.2016.06.006
42. Cohen E, Kaufmann RK. Early childhood mental health consultation: National Technical Assistance Center for Children's Mental Health; 2000.

43. Upshur C, Wenz-Gross M, Reed G (2009) A pilot study of early childhood mental health consultation for children with behavioral problems in preschool. Early Child Res Q 24(1):29-45

44. Raver CC, Knitzer J. 2002 Ready to enter: What research tells policymakers about strategies to promote social and emotional school readiness among three-and four-year-old children

45. Zero to Three. Early Childhood Mental Health Consultation: Policies and Practices to Foster the Social-Emotional Development of Young Children Zero to Three2016 [cited 2021 October]. Available from: https://www.zerotothree.org/resou rces/1694-early-childhood-mental-health-consultation-polic ies-and-practices-to-foster-the-social-emotional-developmentof-young-children.

46. Duran F, Hepburn K, Irvine M, Kaufmann R, Anthony B, Horenn $\mathrm{N}$ et al (2009) What works? A study of effective early childhood mental health consultation programs. Georgetown University. Center for Child and Human Development, Washington, DC

47. Reyes CR, Gilliam WS (2021) Addressing challenging behaviors in challenging environments: Findings from Ohio's early childhood mental health consultation system. Dev Psychopathol 33(2):634-646

48. Hoffmann E, Ewen D. 2007 Supporting families, nurturing young children: Early Head Start programs in 2006. CLASP Policy Brief (Head Start Series). 9.

49. Ranscombe P (2020) Rural areas at risk during COVID-19 pandemic. Lancet Infect Dis 20(5):545. https://doi.org/10.1016/ s1473-3099(20)30301-7

50. Human J, Wasem C (1991) Rural mental health in America. Am Psychol 46(3):232-9. https://doi.org/10.1037//0003-066x.46.3. 232

51. CDC. Rural Communities CDC2021 [cited 2021]. Available from: https://www.cdc.gov/coronavirus/2019-ncov/need-extra-preca utions/other-at-risk-populations/rural-communities.html.

52. CDC. Health Equity Considerations and Racial and Ethnic Minority Groups CDC2020 [cited 2021]. Available from: https://www. cdc.gov/coronavirus/2019-ncov/community/health-equity/raceethnicity.html?CDC_AA_refVal=https $\% 3 \mathrm{~A} \% 2 \mathrm{~F} \% 2 \mathrm{Fwww} . c d c$. gov $\% 2$ Fcoronavirus $\% 2$ F2019-ncov\%2Fneed-extra-precautions $\%$ 2Fracial-ethnic-minorities.html.

53. Warren JR (2009) Socioeconomic status and health across the life course: a test of the social causation and health selection hypotheses. Soc Forces. 87(4):2125-53. https://doi.org/10.1353/sof.0. 0219

54. Perry MJ (1996) The relationship between social class and mental disorder. J Prim Prev 17(1):17-30. https://doi.org/10.1007/bf022 62736

55. Wang H, Yang XY, Yang T, Cottrell RR, Yu L, Feng X et al (2015) Socioeconomic inequalities and mental stress in individual and regional level: a twenty one cities study in China. Int J Equity Health 14:25. https://doi.org/10.1186/s12939-015-0152-4

56. Parker K, Minkin R, Bennett J. 2020 Economic fallout from COVID-19 continues to hit lower-income Americans the hardest. Pew Research Center. 21.

57. Schwartz AE, Rothbart MW (2020) Let them eat lunch: The impact of universal free meals on student performance. J Policy Anal Manage 39(2):376-410

58. Bitler MP, Seifoddini A (2019) Health impacts of food assistance: evidence from the United States. Annu Rev Res Econ 11:261-287

59. Zhou X, Snoswell CL, Harding LE, Bambling M, Edirippulige S, Bai X et al (2020) The role of telehealth in reducing the mental health burden from COVID-19. Telemed e-Health 26(4):377-379 
60. Ohannessian R, Duong TA, Odone A (2020) Global telemedicine implementation and integration within health systems to fight the COVID-19 pandemic: a call to action. JMIR Public Health Surveil 6(2):e18810

61. Smith AC, Thomas E, Snoswell CL, Haydon H, Mehrotra A, Clemensen J et al (2020) Telehealth for global emergencies: Implications for coronavirus disease 2019 (COVID-19). J Telemed Telecare 26(5):309-313

62. Loades ME, Chatburn E, Higson-Sweeney N, Reynolds S, Shafran R, Brigden A et al (2020) Rapid systematic review: the impact of social isolation and loneliness on the mental health of children and adolescents in the context of COVID-19. J Am Acad Child Adolesc Psychiatry. https://doi.org/10.1016/j.jaac.2020.05.009

63. Racine N, Cooke JL, Eirich R, Korczak DJ, McArthur B, Madigan S (2020) Child and adolescent mental illness during COVID-19: A rapid review. Psychiatr Res. https://doi.org/10.1016/j.psychres. 2020.113307
64. Guessoum SB, Lachal J, Radjack R, Carretier E, Minassian S, Benoit L et al (2020) Adolescent psychiatric disorders during the COVID-19 pandemic and lockdown. Psychiatr Res. https://doi. org/10.1016/j.psychres.2020.113264

65. da Silva Junior FJG, de Souza Monteiro CF, Costa APC, Campos LRB, Miranda PIG, de Souza Monteiro TA et al (2020) Impact of COVID-19 pandemic on mental health of young people and adults: a systematic review protocol of observational studies. BMJ Open 10(7):e039426

Publisher's Note Springer Nature remains neutral with regard to jurisdictional claims in published maps and institutional affiliations. 